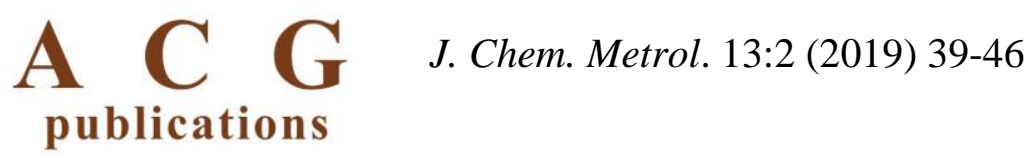

\title{
Ultra-fast liquid chromatography method for the determination of ticagrelor in pharmaceutical formulations and spiked plasma samples
}

\author{
Cem Önal ${ }^{1 *}$ and Ş. Evrim Kepekçi Tekkeli $\oplus^{2}$
}

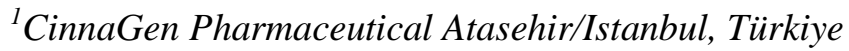 \\ ${ }^{2}$ Bezmialem Vakif University, Faculty of Pharmacy, Department of Analytical Chemistry, Fatih, Istanbul, \\ Türkiye
}

(Received October 31, 2019; Revised November 11, 2019; Accepted November 19, 2019)

\begin{abstract}
This article aims to present a sensitive, and precise stability-indicating ultra fast liquid chromatographic method, which was developed to determine ticagrelor (TCG) in pharmaceutical formulations and spiked plasma samples. Chromatographic separation was achieved under isocratic elution by using a C18 column $(100 \times 4 \mathrm{~mm}$, $3 \mu \mathrm{m})$ and a mixture of acetonitrile and phosphoric acid solution (adjusted to $\mathrm{pH} 3.0$ using triethylamine) (55:45, v/v) at a flow rate of $0.7 \mathrm{~mL}$ per minute. The analyte was detected at a wavelength of $254 \mathrm{~nm}$, using a photodiode array detector (PDA). The retention time for TCG was found out to be about $3.5 \mathrm{~min}$. As required by the International Conference on Harmonization guidelines, the drug was exposed to different stress conditions; including hydrolysis (acid, alkaline), oxidation, photolysis and thermal degradation. This currently developed method was validated by evaluating the specificity, linearity, precision, accuracy, robustness, and system suitability. The method was determined to be linear in a drug concentration range of $0.5-200 \mu \mathrm{g} / \mathrm{mL}$ with the correlation coefficient of 0.9996 . The proposed method was applied successfully to the analysis of TCG in spiked human plasma with good recovery. The method can successfully applied for determination of TCG in pharmaceutical formulation and spiked plasma samples.
\end{abstract}

Keywords: Ticagrelor; UFLC; stability-indicating; degradation; method validation; plasma samples. (C) 2019 ACG Publications. All rights reserved.

\section{Introduction}

Antiplatelet therapy with $\mathrm{P} 2 \mathrm{Y} 12$ receptor antagonists is the key pharmacological treatment for the acute coronary syndrome. Ticagrelor (1S,2S,3R,5S)-3-[7\{[(1R,2S)-2- (3, 4 - difluorophenyl) cyclopropyl] amino -5 -(propylthio)-3H-[1,2,3]-triazolo[4,5d] pyrimidin-3-yl]-5-(2-hydroxyethoxycyclo-pentane-1,2diol) (Figure 1) is an orally administered and direct-acting reversible antagonist of the P2Y12 receptor. The mechanism of action of TCG occurs via the inhibition of ADP-induced platelet aggregation [1]. Ticagrelor (TCG) displays a predictable pharmacokinetic profile after being rapidly absorbed following oral administration [2]. A multiple-dose pharmacokinetic study demonstrated that TCG reached its maximum plasma levels in 1.5-3.0 hours after the oral administration and its half-life ranged from 6.2 to 13.1 hours [3].

\footnotetext{
* Corresponding author E-Mail: cemfox@yahoo.com 


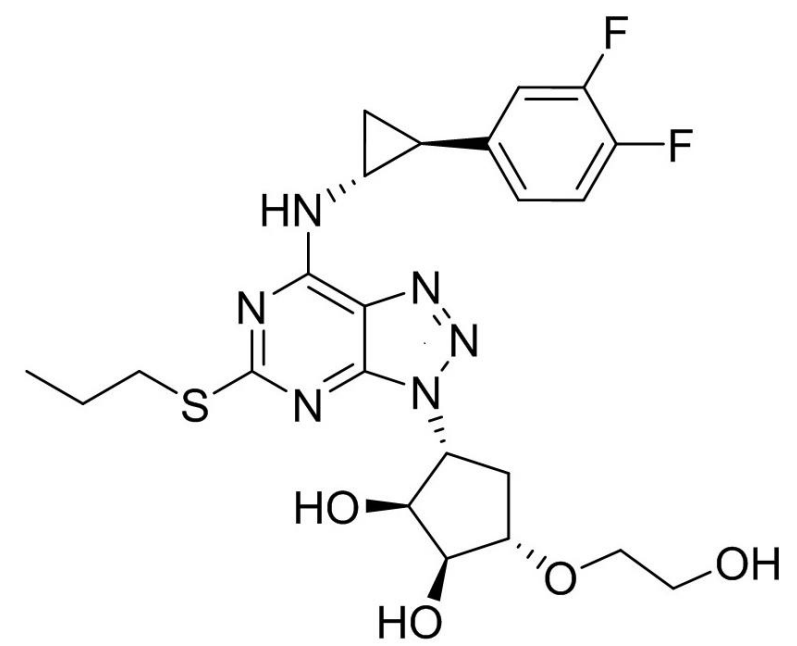

Figure 1. Chemical structure of Ticagrelor

Several analytical methods; including UV-spectrophotometry [4], high-performance liquid chromatography (HPLC) [5], HPLC-mass spectrometry (MS) [6], and HPLC-MS/MS [7] are reported in the literature to quantify TCG in biological fluids and pharmaceutical formulation. However, to the best of our knowledge, no UFLC method has been reported yet for determining the quantity of TCG in dosage forms. UFLC is more favorable compared to conventional HPLC because the time required for the analysis and the mobile phase of drug analysis are shorter in the former. Also, UFLC is associated with superior resolution features. Furthermore, the time-efficiency and cost-efficiency of UFLC for estimating the quantities of several different active pharmaceutical agents in combined pharmaceutical products have already been established [8-11]. Thereby, UFLC offers an advantageous alternative to conventional HPLC. Therefore, in this present study, RP-UFLC was used for determining the quantity of TCG in the tablet dosage form and spiked plasma samples. Stability parameters for the drug were tested by assessing it under forced degradation conditions; including acid-alkali hydrolysis, oxidation, thermal exposure, and exposure to UV radiation. The developed method presented in this present article was validated in compliance with the ICH guidelines for specificity, linearity, precision, accuracy, robustness, stability, and system suitability [12].

\section{Experimental}

\subsection{Chemicals and Reagents}

TCG was kindly supplied by Zhejiang Ausun Pharmaceutical Co., Ltd and its pharmaceutical preparation (BRILINTA Film Tablet ${ }^{\circledR}$ ) containing $90 \mathrm{mg}$ of ticagrelor per film tablet was obtained from local drug store. All chemicals and reagents were of analytical-reagent grade. HPLC grade ultra pure water was prepared by an Elga Purelab Option Q (VWS Deutschland) water purification system.

\subsection{Instrumentation and Chromatographic Conditions}

The chromatographic separations were performed on a Shimadzu LC 20A UFLC (Shimadzu, Kyoto, Japan). A system was consisted of LC 20AB Binary pump, SIL 20AC Autosampler, CTO-10As column oven, and SPD M20A photodiode array (PDA) detector. Chromatographic data were collected and computed by LC Solution system software. Chromatographic separation was achieved on a Inertsustain C18 column ( 4.0 x $100 \mathrm{~mm}, 3 \mu \mathrm{m})$ (GL Sciences, Tokyo-JAPAN) under isocratic elution by using a mixture of acetonitrile and phosphoric acid solution (adjusted to $\mathrm{pH} 3.0$ using triethylamine) $(55: 45, \mathrm{v} / \mathrm{v})$ at a flow rate of $0.7 \mathrm{~mL}$ per minute. The detection was carried out at $254 \mathrm{~nm}$ and the column temperature was set at $30^{\circ} \mathrm{C}$. 


\subsection{Preparation of Stock Solution}

The stock solution of TCG was prepared by dissolving amount corresponding to $10 \mathrm{mg}$ concentration of TCG in asetonitrile:water $(55: 45, \mathrm{v} / \mathrm{v})$ and then diluted with same mixture. The final concentrations of each drug were $0.5-200 \mu \mathrm{g} / \mathrm{mL}$. The stock solutions were stored at $4{ }^{\circ} \mathrm{C}$ and were stable for a month.

\subsection{Preparation of Sample Solution}

\subsubsection{Determination of TCG in Pharmaceutic Formulation}

Tablet powder equivalent to $10 \mathrm{mg}$ of TCG was accurately weighed and transferred into a $50 \mathrm{~mL}$ calibrated flask. About $25 \mathrm{~mL}$ of in asetonitrile:water $(55: 45, \mathrm{v} / \mathrm{v})$ was added and then extraction was performed mechanically for 20 minutes and sonicated for 20 more minutes. The volume was brought to $50 \mathrm{~mL}$ and final solution was filtered. Aliquots of filtrate were diluted further with above solvent mixture then proceed as described under preparation of calibration curve. The nominal contents of the tablets were calculated using either the calibration graph or the corresponding regression equation.

\subsubsection{Determination of TCG in Spiked Plasma Samples}

An aliquot of plasma $(100 \mu \mathrm{L})$ in a centrifuge tube was spiked with different concentrations of TCG and extracted with $200 \mu \mathrm{L}$ of acetonitrile [6].The organic phases were evaporated to dryness in a water bath at $50^{\circ} \mathrm{C}$. The residual mass was reconstituted with $0.2 \mathrm{~mL}$ mobile phase. The percentage recoveries were calculated by using the corresponding calibration graphs for plasma.

\subsection{Method Validation}

The analytical method development and validation were performed according to the International Council on Harmonization (ICH) guidelines [13]. The methods were validated with the following parameters: specificity, linearity, range, precision, accuracy, limit of detection, and quantification.

\subsubsection{Linearity}

The linearity of the method was established for TCG. The solution of TCG was prepared at five different concentrations from 0.5 to $200 \mu \mathrm{g} / \mathrm{mL}$ of analyte concentration. The regression line was plotted with area versus concentration using the method of least squares analysis. The values of the slope and Yintercept of the plot were calculated.

\subsubsection{Limit of Detection and Limit of Quantitation}

The limit of detection (LOD) and the limit of quantitation (LOQ) were determined based on the 3.3 and 10 times the standard deviation of the response, respectively, divided by the slope of the calibration curve.

\subsubsection{Precision}

The precision of the method was determined in terms of intra-day precision and inter-day precision. The inter- and intra-day precisions were examined by analysis of TCG with the three concentrations $(\mathrm{n}=5)$ for five consecutive days. The precision was given as the relative standard deviation $(\mathrm{RSD} \%)$.

\subsubsection{Specificity}

The stress degradation studies were performed according to the ICH guidelines Q1A (R2) (11) for testing the specificity and the efficacy of the proposed method developed to indicating stability. In this 
present study, standard TCG solution samples of $1 \mathrm{mg} / \mathrm{mL}$ concentration were subjected to forced degradation test under acidic $\left(1 \mathrm{~N} \mathrm{HCl}\right.$ at $80^{\circ} \mathrm{C}$ for $1 \mathrm{~h}$ ), basic $\left(1 \mathrm{~N} \mathrm{NaOH}\right.$ at $80^{\circ} \mathrm{C}$ for $\left.1 \mathrm{~h}\right)$, and oxidation conditions $\left(3.0 \% \mathrm{v} / \mathrm{v} \mathrm{H}_{2} \mathrm{O}_{2}\right.$ at room temperature for $1 \mathrm{~h}$ ). After the acid and base degradation samples were neutralized with $1 \mathrm{~N} \mathrm{NaOH}$ and $1 \mathrm{~N} \mathrm{HCl}$, respectively; the diluting solution was added to make up to volume. To carry out the thermal stress study, the drug product was exposed to $105^{\circ} \mathrm{C}$ for a period of up to 4 hours in a temperature-controlled oven. Photolytic degradation was tested by exposing the drug to daylight for 24 hours. After the test solutions were exposed to above mentioned stress degradation conditions for pre-determined periods, they were diluted with the acetonitrile:water $(55: 45, \mathrm{v} / \mathrm{v})$ solution. Then, the elicited degradation samples were analyzed with the UFLC method as described in the chromatographic conditions. A peak purity test was performed using a PDA detector in all stress-exposed test samples to determine the TCG peaks.

\subsubsection{Accuracy}

The accuracy of method was determined by calculating recoveries by spiking method. Known amount of standard solutions of $10.0,50.0,150.0 \mu \mathrm{g} / \mathrm{mL}$ were spiked with known amount sample solutions $(20 \mu \mathrm{g} / \mathrm{mL})$. The amount was estimated by the regression equation of the calibration curve.

\subsubsection{Robustness}

The robustness of the method was studied by changing the method parameters deliberately; including the flow rate of the mobile phase, detection wavelength, and organic phase composition. Solution stability of the drug was assessed in the mobile phase by exposing the drug solution at ambient conditions for 24 hours.

\section{Results and discussion}

\subsection{Chromatographic Conditions}

A variety of mobile phase compositions were used while carrying out several phases of the study. Chromatographic separation was achieved with a mixture of acetonitrile and phosphoric acid solution (adjusted to $\mathrm{pH} 3.0$ using triethylamine) $(55: 45, \mathrm{v} / \mathrm{v})$ at a flow rate of $0.7 \mathrm{~mL}$ per minute on a $\mathrm{C} 18$ column $(100 \times 4 \mathrm{~mm}, 3 \mu \mathrm{m})$ at the column temperature of $30^{\circ} \mathrm{C}$. Figure $\mathrm{S} 1$ shows the typical chromatograms obtained during this study.

\subsection{Method Validation}

The validation of the optimized method was performed in agreement with the ICH guidelines [19]. The following parameters were considered: specificity, linearity, accuracy, precision, LOD and LOQ, and robustness.

\subsubsection{Linearity}

The solutions for the linearity test were prepared from the solution of TCG at six different levels of concentration ranging from $0.5-200 \mu \mathrm{g} / \mathrm{mL}$. The calibration curve was created by the plotting the substance area versus the concentration. The correlation coefficients, slopes and y-intercepts of the calibration plots were obtained and reported. Calibration plots for the seven related substances were found out to be linear over the ranges tested. The correlation coefficients were found to be at values of $>0.999$ for all the components (Table 1).

\subsubsection{Limit of Detection and Limit of Quantitation}

The LOQ and LOD were measured following formula (according to ICH Q2 (R1)) recommendation [19]. The formula has been shown as; 


$$
\mathrm{LOD}=3.3 \mathrm{SD} / \text { slope } \quad \mathrm{LOQ}=10 \mathrm{SD} / \text { slope } \quad \text { (Eq. } 1)
$$

where SD is the standard deviation of the intercept. The LOD and LOQ values shown in Table 1 suggest that the developed methods are sensitive to determine TCG.

\subsubsection{Precision}

The precision studies were carried out for a period of five consecutive days by analyzing the quantity of TCG (each $n=5$ ). The RSD values were found to be in the range of $0.82 \%$ for intra-day precision and they were in the range of $1.11 \%$ for inter-day precision. All these values were below $2 \%$, confirming that the method was precise. The results of the tests have been shown in Table 1 .

Table 1. Regression, precision, limit of detection (LOD) and limit of quantification (LOQ) data

\begin{tabular}{|c|c|c|c|c|c|c|}
\hline $\begin{array}{c}\text { Regression } \\
\text { equation }\end{array}$ & $\begin{array}{c}\text { Correlation } \\
\text { coefficient }\end{array}$ & $\begin{array}{c}\text { Linearity range } \\
(\mu \mathrm{g} / \mathrm{mL})^{\mathrm{c}}\end{array}$ & LOD & LOQ & $\begin{array}{c}\text { Intraday } \\
{\text { precision }(\mathbf{R S D})^{\mathrm{c}}}^{\mathrm{c}}\end{array}$ & $\begin{array}{c}\text { Interday } \\
\text { Precision }(\text { RSD) }\end{array}$ \\
\hline$y=13545 x+18562$ & 0.9996 & $0.5-200$ & 0.032 & 0.167 & 0.82 & 1.11 \\
\hline
\end{tabular}

${ }^{\mathrm{a}}$ Average of five determinatons; ${ }^{\mathrm{c}} \mathrm{n}=5$; ${ }^{\mathrm{d}}$ Results of five different days

\subsubsection{Specificity}

Forced degradation samples under the above mentioned stress conditions were analyzed at an initial concentration of $1 \mathrm{mg} / \mathrm{mL}$. The drug was exposed to acidic, alkaline, oxidative, thermal, and daylights conditions for pre-determined periods. After the exposure to basic hydrolysis in $1.0 \mathrm{M} \mathrm{NaOH}$ solution at $80{ }^{\circ} \mathrm{C}$ for an hour, further peaks were detected from 0.2 to $0.6 \mathrm{~min}$, and the drug degradation was found out to be $83.3 \%$.

(A)

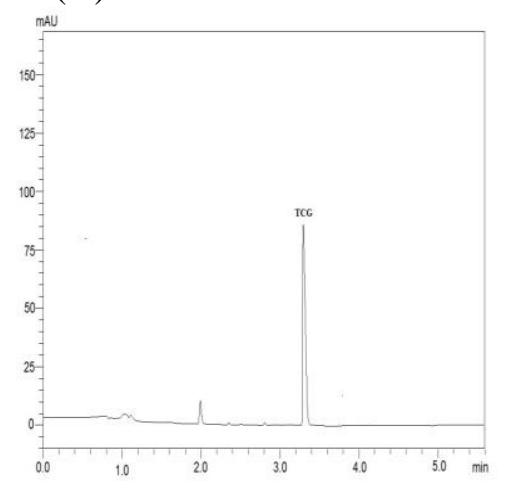

(D)

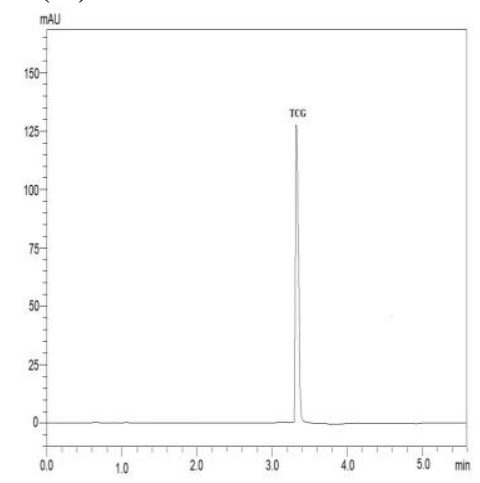

(B)

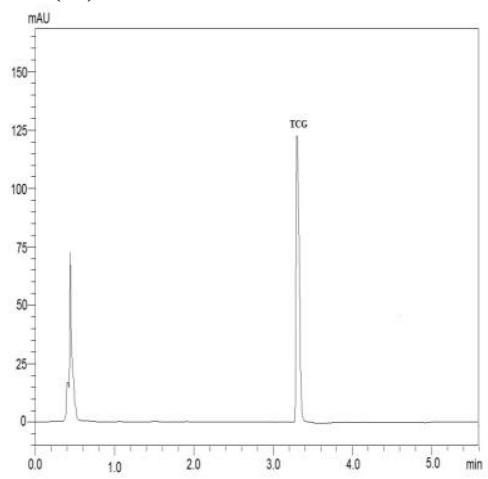

(E)
(C)

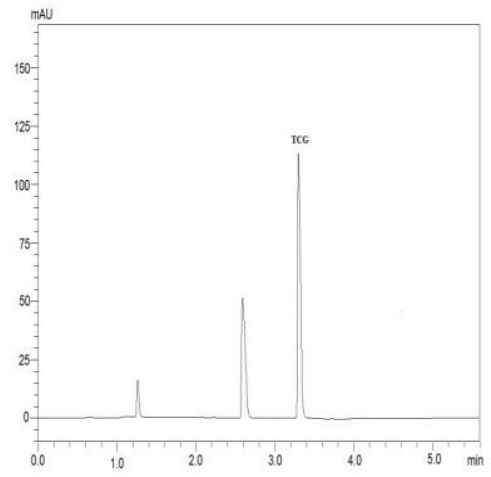

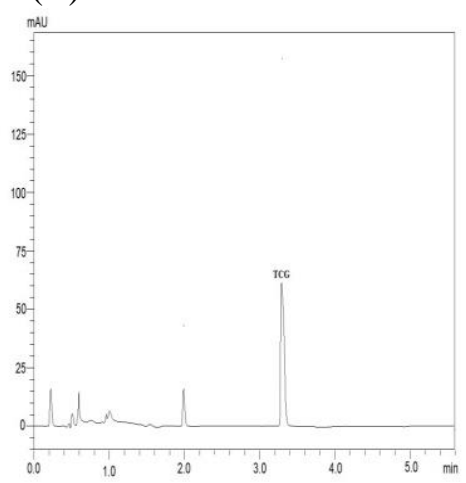

Figure 2. Chromatograms of TCG $50 \mu \mathrm{g} / \mathrm{mL}$ (A) acid-degraded drug, (B) base-degraded drug, (C) oxidation-degraded drug, (D) thermal-degraded drug and (E) exposure the daylight 
The acidic hydrolysis was carried out with $1.0 \mathrm{M} \mathrm{HCl}$ at $80{ }^{\circ} \mathrm{C}$ for 1 hour, leading to an additional small peak in 2.0 minutes and the drug degradation was observed to be $56.6 \%$. After 24-hour exposure to daylight, an additional peak was detected from 0.2 to $2.0 \mathrm{~min}$ and the drug degradation of was found out to be almost $40 \%$. The thermal degradation at $105^{\circ} \mathrm{C}$ for 4 hours led to a drug degradation of $80 \%$. To conduct the oxidative degradation, a $3 \% \mathrm{H}_{2} \mathrm{O}_{2}$ solution was used and the sample solution was left at room temperature for 1 hour. Then, two peaks were observed around 1.2 and 2.6 minutes and the degradation was $80 \%$. A PDA detector was used in order to ensure the homogeneity of the TCG peaks (Figure 2). The results demonstrated that additional peaks were well resolved from the TCG peak (Table 2).

Table 2. Forced degradation data of validated method

\begin{tabular}{lccc}
\hline Stress Condition & Recovery $\mathbf{( \% )}$ & Purity index & Purity Threshold \\
\hline Acid hydrolysis & 56.60 & 0.9998 & 0.9999 \\
Base hydrolysis & 83.30 & 0.9999 & 0.9999 \\
Oxidation & 80.00 & 0.9999 & 0.9999 \\
Thermal degradation & 80.00 & 0.9998 & 0.9999 \\
Exposure to the daylight & 40.00 & 0.9999 & 0.9999 \\
\hline
\end{tabular}

\subsubsection{Accuracy}

The standard addition technique was carried out to prove the accuracy of the proposed method. After adding a certain amount $(20 \mu \mathrm{g} / \mathrm{mL})$ of pure sample solution to the $10.0,50.0,150.0 \mu \mathrm{g} / \mathrm{mL}$ concentrations of standard TCG solutions and to the related impurities, the analysis was performed. The percentage recoveries for the drug and impurities ranged from 99.25-100.14\%. The results of the recovery study have been presented in Table 3 .

Table 3. Accuracy results of TCG

\begin{tabular}{cccccc}
\hline Compound & $\begin{array}{c}\text { Nominal value } \\
\text { of substance } \\
\mathbf{a}(\boldsymbol{\mu g} / \mathbf{m L})\end{array}$ & $\begin{array}{c}\text { Spiked amount } \\
\text { of substance } \\
(\boldsymbol{\mu g} / \mathbf{m L})\end{array}$ & $\begin{array}{c}\text { Measured amount of } \\
\text { substance }^{\mathbf{b}}(\boldsymbol{\mu g} / \mathbf{m L}) \\
\left(\text { Mean }^{\prime} \mathbf{S . D .}^{\mathbf{c}}\right)\end{array}$ & $\begin{array}{l}\text { Recovery } \\
(\boldsymbol{\%})\end{array}$ & $\begin{array}{l}\text { RSD } \\
(\boldsymbol{\%})\end{array}$ \\
\hline TCG & 20.00 & 10.00 & $30.09 \pm 0.05$ & 100.30 & 0.17 \\
& & 50.00 & $70.12 \pm 0.14$ & 100.17 & 0.20 \\
& & 150.00 & $170.14 \pm 0.37$ & 100.08 & 0.22 \\
\hline
\end{tabular}

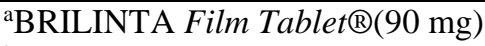

${ }^{\mathrm{b}}$ Five independent analyses.

'Standard deviation

\subsubsection{Robustness}

The method was found to be robust based on the observed changes in the mobile phase flow rate $( \pm 0.1 \mathrm{~mL} / \mathrm{min})$, in the detected wavelength $( \pm 5 \mathrm{~nm})$, and the determined organic phase composition $( \pm 2 \%)$. During the analyses, the mobile phase $\mathrm{pH}(3.0 \pm 0.2)$ and column oven temperature $\left(30 \pm 5^{\circ} \mathrm{C}\right)$ were measured and noted. The study demonstrated that minor variations in the method variables did not significantly affect the results, proving the robustness of the currently proposed method.

The chemical stability of the stock solutions, which were composed of the study compounds in acetonitrile:water $(55: 45, \mathrm{v} / \mathrm{v})$ mixture, was assessed after storing the solutions at room temperature $\left(25^{\circ} \mathrm{C}\right)$ for 48 hours. All of the studied compounds were found out to be stable in the mobile phase for 48 hours at room temperature and in the refrigerator $\left(\right.$ at $\left.4^{\circ} \mathrm{C}\right)$. The stability studies yielded no further peaks in the chromatograms. 


\subsection{Preparation of Sample Solution}

\subsubsection{Determination of TCG in Pharmaceutic Formulation}

The proposed method was applied for the quantitative determination of TCG in the pharmaceutical forms. The obtained results were in agreement with the results specified in the approved labeled content of TCG. (Table 4).

Table 4. Determination of TCG in tablets by the proposed methods $(n=5)$

\begin{tabular}{|c|c|c|c|c|}
\hline Proposed method & $\begin{array}{l}\text { Label claim }^{\mathrm{a}} \\
\text { (mg/per tablet) }\end{array}$ & $\operatorname{Mean}^{b} \pm$ S.D & Recovery (\%) & RSD (\%) \\
\hline & 90.00 & $90.14 \pm 0.26$ & 100.16 & 0.29 \\
\hline
\end{tabular}

${ }^{a}$ BRILINTA Film Tablet $\circledR(90 \mathrm{mg})$

${ }^{\mathrm{b}}$ Five independent analyses.

'Standard deviation

\subsubsection{Determination of TCG in Spiked Plasma Samples}

The Cmax of TCG after administration of $180 \mathrm{mg}$ is reportedly as $1013.1 \pm 277.2 \mathrm{ng} \mathrm{mL}^{-1}$ [13]. With reference to study, the proposed methods could be successfully applied for the determination of TCG in spiked plasma.

The extraction procedures and applying of the proposed methods to plasma samples were described at section 2.4.2. The obtained results shown in Table 5 are satisfactorily accurate and precise.

Table 5. The recoveries of TCG from spiked plasma $(n=5)$

\begin{tabular}{cccc}
\hline $\begin{array}{c}\text { Spiked } \\
(\boldsymbol{\mu g} / \mathbf{m L})\end{array}$ & $\begin{array}{c}\text { Determined } \pm \text { S.D } \\
(\boldsymbol{\mu g} / \mathbf{m L})\end{array}$ & $\begin{array}{c}\text { Recovery } \\
(\boldsymbol{\%})\end{array}$ & $\begin{array}{c}\text { RSD } \\
(\boldsymbol{\%})^{\mathbf{a}}\end{array}$ \\
\hline 0.5 & $0.41 \pm 0.0024$ & 82 & 0.58 \\
1.0 & $0.85 \pm 0.0087$ & 85 & 1.02 \\
2.0 & $1.78 \pm 0.012$ & 89 & 0.67 \\
\hline aFive independent analyses. & & &
\end{tabular}

In conclusion, a new UFLC method is proposed for quantification of a novel active pharmaceutical compound TCG in commercially available pharmaceutical dosage form and spiked plasma samples. According to literature, researchers did not report any UFLC method for establishing stability and quantification of TCG in pharmaceutical preparations. UFLC approach has advantages of higher resolution, faster analytical procedure enabling shorter run time, less amount of mobile phase requirement compared to widely used conventional HPLC. Stability profile of TCG under various stress conditions was investigated through appropriate separation of formed degradation products from parent compound. All degradation products formed under stress conditions were separated from the drug substance appropriately, indicating that the method was suitable to stability indicating. The developed UFLC approach enabled a user friendly and rapid analytical method which is suitable for implementation in stability studies and quality control tests of TCG in pharmaceutical preparations.

Therapeutic drug monitorization is aiming to optimize therapeutic outcome through close follow up of pharmacokinetic profile of the examined drug from selected patient's blood samples. The proposed method was successfully implemented in quantification of TCG in spiked plasma samples and no interference from matrix was observed. This makes pharmacokinetic analysis possible for TCG and this also provides opportunity to carry out bioavailability, bioequivalence studies and TDM approach for such a new drug substance. 
ORCID

Cem Önal: 0000-0002-5840-7386

Ş.Evrim Kepekçi Tekkeli: 0000-0002-1871-017X

\section{Supporting Information}

Supporting information accompanies this paper on http://www.acgpubs.org/journal/journal-ofchemical-metrology

\section{References}

[1] J.J. van Giezen, L. Nilsson, P. Berntsson, B.M. Wissing, F. Giordanetto, W. Tomlinson and P.J. Greasley (2009). Ticagrelor binds to human P2Y(12) independently from ADP but antagonizes ADP-induced receptor signaling and PA, J. Thromb. Haemost. 7(9), 1556-1565.

[2] K. Butler and R. Teng (2010). Pharmacokinetics, pharmacodynamics, safety and tolerability of multiple ascending doses of ticagrelor in healthy volunteers, Br. J. Clin. Pharmacol. 70(1), 65-77.

[3] M. Ambasana, N. Kapuriya, N. Faldu and K. Ladva (2014). Development and validation of a UV spectrophotometric method for the determination of ticagrelor in bulk form, Der Pharmacia Lett. 4, 237-240.

[4] G. Caren, R.L. Pereira, A.S.L. Mendez and C.V. Garcia (2014). Determination of the new antiplatelet agent ticagrelor in tablets by stability-indicating HPLC method, Curr. Pharmaceut. Anal. 10(4), 279-283.

[5] A. Ambasana, N.P. Kapuriya, , K.M. Mangtani and K.D. Ladva (2016). An improved assay method for the estimation of ticagrelor hydrochloride by reverse phase liquid chromatography, Int. J. Pharm. Sci. Res. 7(5), 2009-2014.

[6] H. Sillén, M. Cook and P. Davis (2010). Determination of ticagrelor and two metabolites in plasma samples by liquid chromatography and mass spectrometry, J. Chromatogr. B 878(25), 2299-2306.

[7] W. Zhong, X. Wang, L. Tang, L. Mai , X.P. Chen, G. He , Z. Zheng and S. Zhong (2016). Simultaneous determination of Ticagrelor and its metabolites in human plasma and urine using liquid chromatographytandem mass Spectrometry, J. Anal. Toxicol. 40(6), 445-453.

[8] F.S. Bandarkar and I.S. Khattab (2010). Simultaneous estimation of glibenclamide, gliclazide, and metformin hydrochloride from bulk and commercial products using a validated ultra fast liquid chromatography technique, J. Liq. Chromatogr. Relat. Technol. 33, 1814-1830.

[9] N. Sun, J. Wen, G. Lu, Z. Hong, G. Fan, Y. Wu, C. Sheng and W. Zhang (2010). An ultra fast LC method for the determination of iodiconazole in microdialysis samples and its application in the calibration of laboratory-made linear probes, J. Pharm. Biomed. Anal. 51, 248-251.

[10] N. Batta, R.K. Pigili, L.M. Pallapothu and R.P. Yejella (2014). A simple, rapid and sensitive UFLC-MS/MS method for the quantification of oral contraceptive norgestrel in human plasma and its pharmacokinetic applications, Drug Res (Stuttg). 64(9), 462-9.

[11] R. Gannu, V.V. Yamsani, S.K. Yamsani, C.R. Palem, S. Voruganti and M.R. Yamsani (2009). Development of ultra fast liquid chromatographic method for simultaneous determination of nitrendipine and carvone in skin diffusate samples, J. Pharm. Biomed. Anal. 50(5), 1080-4.

[12] I.H.T Guideline (2005) Validation of Analytical Procedures: Text and Methodology, Q2 (R1)1 (2005)

[13] G.M. Rosa, D. Bianco, A. Valbusa, L. Massobrio, F. Chiarella and C. Brunelli (2016). Pharmacokinetics and pharmacodynamics of ticagrelor in the treatment of cardiac ischemia, Expert. Opin. Drug. Metab. Toxicol. 12(12), 1491-1502.

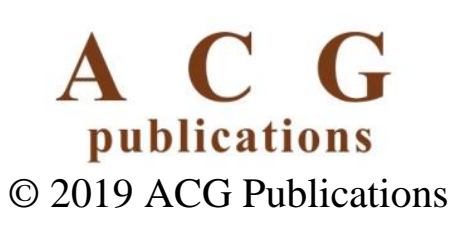

